\title{
L-Alanyl-L-alanine Conformational Changes Induced by pH As Monitored by the Raman Optical Activity Spectra
}

\author{
Jiř́i Šebek, ${ }^{\dagger}$, Josef Kapitán, ${ }^{\dagger} \S$ Jaroslav Šebestík, ${ }^{\dagger}$ Vladimír Baumruk, ${ }^{\S}$ and Petr Bouř ${ }^{*} \dagger$ \\ Institute of Organic Chemistry and Biochemistry, Academy of Sciences, Flemingovo náměstí 2, 166 10, Prague \\ 6, Czech Republic, Faculty of Mathematics and Physics, Institute of Physics, Charles University, Ke Karlovu 5, \\ 12116, Prague, Czech Republic, and Department of Analytical Chemistry, Institute of Chemical Technology, \\ Technická 5, 166 28, Prague 6, Czech Republic
}

Received: March 26, 2009; Revised Manuscript Received: May 13, 2009

\begin{abstract}
Fine effects of the hydration, charge, and conformational structural changes in L-alanyl-L-alanine (Ala-Ala) dipeptide were studied with the aid of Raman and Raman optical activity (ROA) spectra. The spectra were recorded experimentally and analyzed by means of density functional computations. $\mathrm{A}^{15} \mathrm{~N}$ and ${ }^{13} \mathrm{C}$ isotopically labeled analogue was synthesized and used to verify the vibrational mode assignment. Calculated shifts in vibrational frequencies for isotopically labeled molecule agreed well with the experiment. The assignment made it possible to scale computed vibrational frequencies and extract better structural information from the intensities. Solvent modeling with clusters obtained from molecular dynamics led to a qualitatively correct inhomogeneous broadening of Raman spectral lines but did not bring a convincing improvement of ROA signal when compared to a standard dielectric solvent correction. In comparison with the zwitterionic form, charged anionic and cationic dipeptides provided spectral variations that indicated different conformational behavior. Only minor backbone conformational change occurs in the cation, whereas the results indicate the presence of more anion conformers differing in the rotation of the $\mathrm{NH}_{2}$ group and the backbone $\psi$-angle. These findings are in agreement with previous electronic circular dichroism (ECD) and NMR studies. The results confirm the large potential of the ROA technique for the determination of final details in molecular structure and conformation.
\end{abstract}

\section{Introduction}

Many functions of important biopolymers, such as peptides and proteins, are closely intertwined with their conformation. Therefore, the molecules are often conveniently studied by spectroscopic techniques utilizing molecular optical activity, which is extremely sensitive to conformational changes. ${ }^{1-3}$ The Raman optical activity (ROA) is especially suitable for biologically relevant molecules, as it enables one to monitor their behavior in natural aqueous environment. ROA spectroscopy detects intensity differences in the Raman scattering of rightand left-circularly polarized light. ${ }^{4-7}$ Additionally, the inhomogeneous band broadening of the Raman and ROA spectral lines of small polar molecules could be recently interpreted in terms of molecular flexibilities. ${ }^{8,9}$

As the previous $\mathrm{NMR}^{10}$ and $\mathrm{CD}^{11,12}$ studies indicate subtle changes in the L-alanyl-L-alanine (Ala-Ala) geometry upon $\mathrm{pH}$ change, in this work, we analyze the variances of the Raman and ROA spectra of the zwitterionic (AAZW), anionic $\left(\mathrm{AA}^{-}\right.$), and cationic $\left(\mathrm{AA}^{+}\right)$dipeptide (Figure 1) to relate them to the conformational differences. The ${ }^{15} \mathrm{~N}^{13} \mathrm{C}$ isotope analogue was synthesized and used for a more reliable assignment of the AAZW vibrational transitions of the backbone modes, whereas the more usual deuteration of the dialanine investigated before ${ }^{13}$ enabled classification of the hydrogen stretching vibrations in particular. Most experimental spectral features could be ex-

* To whom correspondence should be addressed. E-mail: bour@uochb. cas.cz.

$\dagger$ Academy of Sciences.

* Institute of Chemical Technology.

$\S$ Charles University.

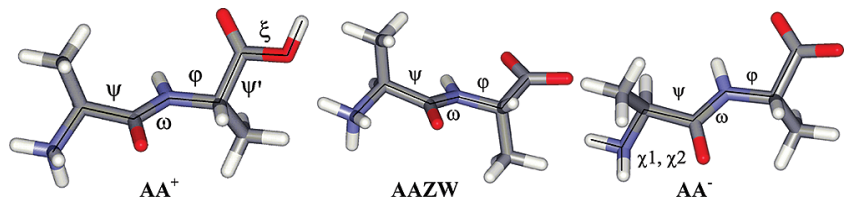

Figure 1. Three ionic Ala-Ala forms and the main torsion angles. For $\mathrm{AA}^{-}$an average angle $\chi=\left(\chi_{1}+\chi_{2}\right) / 2$ was used to characterize rotation of the whole $\mathrm{NH}_{2}$ group.

plained on the basis of molecular dynamics (MD) and density functional theory (DFT) computations of molecular geometry and the spectra. The results generally confirm the NMR and $\mathrm{CD}$ findings and provide additional information about some geometry features, as the vibrational spectra are more sensitive to fine conformational deviations. Typically, the CD signal is significantly modified by the solvent, while the time scale of NMR does not allow seeing signals from individual conformers. On the other hand, the vibrational Raman spectroscopy is more local and the optical response fast enough for an independent conformer sampling.

The Ala-Ala (AA) molecule and similar short peptides have served as convenient prototypes of biologically relevant polar and hydrated systems for a long time. Behavior of longer peptide molecules would be difficult to model with comparable accuracy. Previous spectroscopic studies of AA included, for example, infrared multiphoton dissociation spectroscopy, ${ }^{14} \mathrm{CD},{ }^{11}$ NMR, vibrational circular dichroism (VCD), ${ }^{13,15}$ and also Raman and ROA. ${ }^{13,16}$ Computational studies ${ }^{17,18}$ unambiguously confirm the importance to involve the aqueous environment in the modeling, as it stabilizes the conformation and charge states. 
Even for a less polar AA dipeptide analogue ${ }^{19}$ the ROA spectra suggest that shorter peptides behave differently than longer ones, and their interaction with the solvent is more important for their conformation.

In comparison with other experimental techniques, ROA has several specifics. Due to the fast molecular response to the light, the ROA spectrum represents a sum of contributions from individual conformers, ${ }^{20}$ while the additivity is often lost in NMR due to the relaxation processes. ${ }^{21}$ Many well-resolved vibrational transitions can be measured, in contrast to a broad signal usually seen in electronic absorption and CD. In comparison to Raman scattering, ROA spectra are much more sensitive to molecular structural details. Interpretation of ROA can still be achieved by an empirical comparison to spectra of similar molecules or to the Raman, IR, or VCD signal., ${ }^{2,4}$ Nevertheless, today it is almost entirely dependent on quantum chemical computations. ${ }^{22,23}$ Although the DFT methods and approximate solvent models made it feasible to treat larger molecules, calculations become notoriously difficult for flexible and hydrated systems, where many conformers and interaction with the solvent have to be taken into account.

Typically, the computations are not accurate enough to reproduce all spectral features. Particularly the solvent is difficult to simulate, and both continuum and cluster models provide a limited accuracy. In such cases statistical methods are helpful in an objective comparison of the simulated and experimental spectra, and extraction of the structural information encoded in the Raman and ROA intensities. In the present study we attempted to take into account the dynamics, interaction with the solvent, and conformational equilibria of the Ala-Ala peptide. This provided realistic band dispersion and in general a more faithful representation of molecular behavior than previous rigid one-geometry model. ${ }^{16}$ Statistical decomposition of the experimental spectra into calculated subspectra ${ }^{9,20}$ could at least partially overcome the current limited precision of the simulation and experimental noise. Although not all details about the molecular geometry and dynamics were definitely revealed, we consider this study as a step on the path toward a better structural resolution achieved by the optical techniques.

\section{Method}

Experiment. Isotopically labeled L-Ala-L-Ala dipeptide was prepared from L-alanine $\left({ }^{13} \mathrm{C}, 98 \% ;{ }^{15} \mathrm{~N}, 98 \%\right.$, Stable Isotopes, Inc.). Conventional peptide synthesis in solution was employed with benzyloxycarbonyl protection, ${ }^{24,25}$ where the zwitterionic dipeptide was obtained by hydrogenolysis on Pd-black. ${ }^{26}$ Details of the synthesis are given elsewhere. ${ }^{27}$ Unlabeled L-Ala-L-Ala was purchased from Sigma-Aldrich and used without further purification. Zwitterionic forms for the measurement were obtained by dissolving the peptide in deionized water $(\mathrm{pH} 6.5$, $2.1 \mathrm{~mol} / \mathrm{L}$ ). Charged forms (for unlabeled peptide only) were obtained from Ala-Ala by titration with $2 \mathrm{M} \mathrm{NaOH}$ (final $\mathrm{pH}$ $\sim 13$ ) and $6 \mathrm{M} \mathrm{HCl}(\mathrm{pH} \sim 1)$, for final concentrations of $\sim 1$ mol/L. Backscattered ROA and Raman spectra were measured at room temperature $(\sim 293 \mathrm{~K})$ on a spectrometer constructed at Charles University. ${ }^{28,29}$ The instrument is based on a fast stigmatic spectrograph HoloSpec HS-f/1.4 (Kaiser Optical Systems) equipped with a holographic transmission grating and a back-illuminated CCD detection system (Roper Scientific, $1340 \times 100$ pixels $)$. The samples were held in $5 \times 5 \times 12 \mathrm{~mm}$ rectangular quartz micro-fluorescence-cell with an inner path length $5 \mathrm{~mm}$ and recorded with $514.5 \mathrm{~nm}$ excitation wavelength, $6.5 \mathrm{~cm}^{-1}$ spectral resolution, $430 \mathrm{~mW}$ laser power at the sample, and a total acquisition time of approximately $15 \mathrm{~h}$.
Computations. Starting peptide geometry was taken from refs 10 and 12. For optimized geometries, harmonic spectral intensities were calculated with the Gaussian program. ${ }^{30}$ Harmonic force fields and Raman and ROA tensors were obtained using the B3LYP ${ }^{31,32}$ functional and the $6-31+\mathrm{G}^{* *}$ or $6-311++\mathrm{G}^{* *}$ Pople-type basis sets, with the CPCM dielectric correction, ${ }^{33}$ which is the Gaussian version of the $\mathrm{COSMO}^{34}$ solvent model. In indicated cases, the Cartesian coordinate transfer ${ }^{35}$ of atomic property tensors was used to combine force field and intensity tensors computed at different levels of approximation.

Clusters of Ala-Ala with water molecules were obtained from molecular dynamics (MD) simulations described earlier. ${ }^{12}$ Geometries of the peptide with hydrogen-bonded waters were partially optimized in normal mode coordinates. ${ }^{36,37}$ Normal modes within -300 and $300 \mathrm{~cm}^{-1}$ were fixed (imaginary frequencies are considered as a negative), while the remaining ones were fully relaxed. As discussed previously, ${ }^{36,37}$ the constrained minimization of energy in the normal mode coordinates is a powerful tool for vibrational spectroscopy, in particular efficient for clusters, where it preserves to a high degree the original (MD) geometry while the spectroscopically important motions are fully relaxed. Note that for the given constraint all frequencies below $-300 \mathrm{~cm}^{-1}$ are eliminated during the optimization. The gradients were calculated by the TURBOMOLE program set ${ }^{38}$ at the B3LYP/COSMO/6$31+\mathrm{G}^{* *}$ level. TURBOMOLE provided numerically more stable convergence than Gaussian; for optimized geometries the same wavenumbers within $\sim 1 \mathrm{~cm}^{-1}$ were obtained by both programs. Polarizability (for whole clusters) and optical activity tensor derivatives (dipeptide only) were computed by Gaussian and combined using the Cartesian transfer techniques. ${ }^{35}$ For each dipeptide form spectra of ten clusters were averaged to minimize the influence of water positions.

With the aid of our software, the experimental spectra were analyzed by comparison with the calculations. Observed vibrational bands were assigned to computed harmonic normal modes by a simultaneous comparison of the theoretical and observed Raman and ROA intensities. For the zwitterion the assignment could be verified using also the isotopically labeled peptide. When indicated, the calculated frequencies were scaled according to the experiment. According to the usual formulas, $1,9,23,39,40$ backscattering nonresonance Raman and ROA intensities were regenerated from the scaled constants and ab initio polarizability derivatives, using Lorentzian band full width at a half-height of $10 \mathrm{~cm}^{-1}$. The theoretical intensities were multiplied by a common arbitrary factor to adjust them to the measured intensities.

The agreement of simulated $S_{i}(\omega)$ and experimental $S_{\mathrm{e}}(\omega)$ Raman and ROA spectra was judged from a modified sum of absolute deviations,

$$
\begin{array}{r}
\delta=\sum_{j}\left|\tilde{S}_{i}\left(\omega_{j}\right)-k \tilde{S}_{\mathrm{e}}\left(a \omega_{j}+\Delta\right)\right|+a_{k}(k-1)^{2}+ \\
a_{a}(a-1)^{2}+a_{\Delta} \Delta^{2}
\end{array}
$$

where $\tilde{S}(\omega)$ are the corresponding normalized spectral curves $\left(\int|\tilde{S}(\omega)| \mathrm{d} \omega=1\right)$, and the adjustment parameters for frequencies $(a, \Delta)$ and intensities $(k)$ were determined by a nonlinear iterative minimization of $\delta$. The index $j$ corresponds to the discrete spectral points; the error is obviously dependent on the number of points and the analysis meaningful for spectra recorded in the same range only. For a perfect agreement of $a=k=1$ and $\Delta=0$, adjusting was introduced to allow for an error of the 
TABLE 1: Calculated Torsion Angles and Relative Energies of the Selected AA Dipeptide Conformers ${ }^{a}$

\begin{tabular}{lccccccc}
\hline $\begin{array}{c}\text { peptide } \\
\text { (conformer) }\end{array}$ & $\psi$ & $\varphi$ & $\omega$ & $\chi$ & $\psi^{\prime}$ & $\Delta E$ & $\begin{array}{c}\Delta E+ \\
\mathrm{ZPE}\end{array}$ \\
\hline $\mathrm{AAZW}$ & 148 & -155 & 174 & & & & \\
$\mathrm{AA}^{+}(\mathbf{1})$ & 150 & -128 & 177 & & 170 & 0.0 & 0.0 \\
$\mathrm{AA}^{+}(\mathbf{2})$ & 150 & $-118^{b}$ & 176 & & 169 & 0.1 & 0.5 \\
$\mathrm{AA}^{+}(\mathbf{3})$ & 149 & -123 & 176 & & -10 & 0.8 & 1.2 \\
$\mathrm{AA}^{+}(\mathbf{4})$ & 150 & -94 & 175 & & 170 & 0.1 & 0.4 \\
$\mathrm{AA}^{+}(\mathbf{5})$ & 148 & -94 & 174 & & -5 & 0.4 & 0.8 \\
$\mathrm{AA}^{-}(\mathbf{1})$ & 132 & -151 & 177 & -3 & & 0.0 & 0.0 \\
$\mathrm{AA}^{-}(\mathbf{2})$ & -20 & -154 & 179 & 45 & & 0.1 & 0.4 \\
$\mathrm{AA}^{-}(\mathbf{3})$ & 128 & -153 & 176 & 121 & & 0.6 & 0.6 \\
$\mathrm{AA}^{-}(\mathbf{4})$ & 7 & -153 & 176 & -35 & & 0.6 & 0.8
\end{tabular}

${ }^{a}$ The angles defined in Figure 1 are given in degrees. The energies $(\Delta E)$ are calculated at the B3LYP/CPCM/6-31+G** level without and with the zero point vibrational energy (ZPE) in $\mathrm{kcal} / \mathrm{mol} .{ }^{b}$ The value was fixed during the optimization.

calculated frequencies. The weights of the quadratic penalty functions were chosen on the basis of previous experience as $a_{k}=1, a_{a}=10$, and $a_{\Delta}=0.01 .^{9,20}$

The experimental spectra were in some cases decomposed into the calculated subspectra, $\tilde{S}_{\mathrm{e}}\left(\omega_{j}\right)=\sum_{i=1 \ldots m} b_{i} s_{i}\left(\omega_{j}\right)$. Preoptimized subspectra $s_{i}\left(\omega_{j}\right)=k \tilde{S}_{i}\left(a \omega_{j}+\Delta\right)$ were used, but the optimization was found to be unimportant. The use of the normalized spectra is based on the assumption that average absolute intensities of different conformers over a larger range of frequencies are the same. While this is in general not true for ROA, in practice such approximation provided reasonable estimates of the conformer ratios. ${ }^{9}$ The coefficients $b_{i}$ were determined from a constrained minimization ${ }^{9,20}$ of $\Delta=\sum_{j}\left(\tilde{S}_{\mathrm{e}}\left(\omega_{j}\right)\right.$ $\left.-\sum_{i=1 \ldots m} b_{i} s_{i}\left(\omega_{j}\right)\right)^{2}+\alpha \sum_{i=1 \ldots m}\left(b_{i}-1 / m\right)^{2}$, with $\sum_{i=1 . . m} b_{i}=1$ and $\alpha=0.02$. The nonzero value of $\alpha$ prevents large negative $b_{i}$ coefficients, forcing them within the $(0,1)$ interval. When indicated, calculated spectra used in the decomposition were scaled on the basis of a direct graphical comparison with experimental Raman and ROA shapes; exact frequencies thus could occasionally deviate from a detailed band-to-band assignment (cf. Table 2 below).

\section{Results and Discussion}

Equilibrium Geometries. Equilibrium geometries and dialanine DFT potential surfaces for all the three charged forms can be found elsewhere. ${ }^{10,12}$ The water environment, presently included as the polarizable continuum correction, is necessary for reliable conformational predictions. ${ }^{17}$ Torsional angles and relative energies of the lowest-energy conformations included in this study are summarized in Table 1 . As discussed previously for AA, ${ }^{27} N$-acetylalanine- $N$-methylamide, ${ }^{19}$ and similar dipeptides, ${ }^{9}$ conformations of these small molecules significantly differ from canonical peptide secondary structures. The zwitterion AAZW adopts only one conformer in solution. ${ }^{10}$ For the cation $\mathrm{AA}^{+}$, apart from the lowest-energy conformation (1), other backbone conformers were investigated, because the potential well is very shallow in the $\varphi$-angle direction (cf. Figure 1 for the angle definition). These were obtained either by fixing the $\varphi$-angle or by an optimization to local minimum. Additionally for $\mathrm{AA}^{+}$, two orientations of the $\mathrm{COOH}$ group were considered differing in the position of the $\mathrm{OH}$ group characterized by the $\psi^{\prime}$ torsion angle. For $\mathrm{AA}^{-}$two backbone conformations $(\mathbf{1}, 2)$ appear almost equally probable, and additional conformers $(3,4)$ can be created by rotation of the $\mathrm{NH}_{2}$ group. The $\mathrm{NH}_{2}$ movement had a little effect on the NMR character- istics ${ }^{10}$ and only caused nonspecific changes in the CD spectra. ${ }^{12}$ As shown below, larger intensity variations are induced in the Raman and ROA bands. The vibrational zero point energy (ZPE, last column of Table 1) somewhat modifies the electronic energies, but because of the expected computational error, it is difficult to draw consequences for exact conformer populations, similarly as for comparable dipeptide systems. ${ }^{9}$

Vibrational Assignments. The calculated (B3LYP/CPCM/ $6-31+G^{* *}$, for the lowest-energy structures in Table 1) and experimental wavenumbers for the three Ala-Ala forms are compared in Table 2. The zwitterion frequencies mostly agree with previous assignments. ${ }^{13,16}$ Presently, we have additionally assigned some peaks below $580 \mathrm{~cm}^{-1}$ and differentiated the experimental ROA peaks (by presenting their frequencies in italics in Table 2). Unfortunately, some modes still cannot be assigned unambiguously as they are weak or overlapped with other vibrations. By comparing the older ${ }^{16}$ and various sets of newer measurements we also found that the absolute accuracy of the Raman band positions $\left(\sim \pm 1 \mathrm{~cm}^{-1}\right)$ is limited because of the incomplete baseline subtraction and resolution of the CCD detector (one pixel may correspond up to $\sim 3 \mathrm{~cm}^{-1}$ ).

Most of the zwitterionic vibrational transitions are conserved also in the anion and cation, obviously except for the terminal groups. For example, only the $\mathrm{C}=\mathrm{O}$ stretching of the $\mathrm{COOH}$ group in the cation $\mathrm{AA}^{+}$can be seen separately in the spectrum at $1727 \mathrm{~cm}^{-1}$, while the two (in and out of phase) $\mathrm{C}=\mathrm{O}$ stretches in $\mathrm{COO}^{-}$in the other two forms vibrate at lower wavenumbers. Similarly, the $\mathrm{NH}_{2}$ group of the anion $\mathrm{AA}^{-}$has unique vibrations; these, however, cannot be so easily identified in the spectrum, because they are mixed and overlapped by other modes. In all the forms the assignment of the bands within $\sim 1400-1750 \mathrm{~cm}^{-1}$ remains particularly incomplete, because of the large number of overlapping $\mathrm{C}-\mathrm{H}$ bending modes $\left(1400-1500 \mathrm{~cm}^{-1}\right.$ ), notoriously weak amide II signal (presumably at $\sim 1550 \mathrm{~cm}^{-1}$ ), and the broadening of the amine $\mathrm{NH}$ bending and carboxyl and amide $\mathrm{C}=\mathrm{O}$ stretching bands caused by the hydrogen-bond formation with the solvent.

Isotopic Effects. Because of the limited accuracy and resolution, spectra of the isotopic AAZW compound significantly contributed to the reliability of the assignment in Table 2. In Figure 2 Raman and ROA spectra of the zwitterion are displayed, as obtained experimentally for the natural (black lines) and labeled analogue (red lines) and as obtained by the B3LYP/CPCM/6-31+G** calculation. Integral Raman intensities are not much affected, but individual peak shifts differ. The molecule becomes heavier and the ${ }^{13} \mathrm{C}{ }^{15} \mathrm{~N}$ labeling causes an overall wavenumber shift to lower values throughout the entire spectral range. The biggest shift of $57 \mathrm{~cm}^{-1}(\sim 3.4 \%)$ is exhibited by the amide I mode ( $\mathrm{C}=\mathrm{O}$ stretching), which is less than the $\left.4.1 \%\left[=(13 / 12)^{1 / 2}-1\right) \times 100 \%\right]$ that might be expected from the carbon mass change, but still slightly more than a $2.3 \%$ change similarly estimated from the reduced mass of the $\mathrm{CO}$ group. ${ }^{41}$ The amide I ${ }^{13} \mathrm{C}$-induced shift is conveniently used to monitor mode coupling and conformation of peptides in IR and vibrational circular dichroism studies ${ }^{42,43}$ In our case, the $\mathrm{C}=\mathrm{O}$ stretching wavenumber shift is not particularly helpful, because the molecule contains only one amide group and the amide I band is well-separated from the other modes. Other peak positions are not so sensitive to the substitution; the $\mathrm{C}-\mathrm{H}$ bending/scissoring band $\left(\sim 1460 \mathrm{~cm}^{-1}\right)$, for example, exhibits a modest shift of $2 \mathrm{~cm}^{-1}$. Visually, it is the lower-frequency $\left(\sim 150-700 \mathrm{~cm}^{-1}\right)$ region that appears to be least affected by the substitution, mainly because these vibrations are dominated by the motion of the $\mathrm{CH}_{3}$ and $\mathrm{NH}_{3}$ groups coupled with the 
TABLE 2: Calculated (B3LYP/CPCM/6-31+G**) and Experimental Vibrational Transition Frequencies (in $\mathrm{cm}^{-1}$ ) in the Three AA Ionic Forms

\begin{tabular}{|c|c|c|c|c|c|c|}
\hline \multicolumn{2}{|c|}{ AAZW } & \multicolumn{2}{|c|}{$\mathrm{AA}^{+}$} & \multicolumn{2}{|c|}{$\mathrm{AA}^{-}$} & \multirow[b]{2}{*}{ assignment $(\nu$, stretching; $\delta$, bending $)$} \\
\hline$\omega_{\mathrm{CAL}}$ & $\omega_{\mathrm{EXP}^{a}}$ & $\omega_{\mathrm{CAL}}$ & $\omega_{\mathrm{EXP}^{a}}$ & $\omega_{\mathrm{CAL}}$ & $\omega_{\mathrm{EXP}^{a}}$ & \\
\hline & & 1756 & 1727 & & & $v(\mathrm{C}=\mathrm{O})$ in $\mathrm{COOH}\left(\mathrm{AA}^{+}\right)$ \\
\hline 1623 & 1620 & 1621 & & 1627 & & $\delta(\mathrm{N}-\mathrm{H})$ \\
\hline 1596 & & & & 1584 & 1597 & $\delta(\mathrm{C}=\mathrm{O}) \mathrm{COO}$, out of phase \\
\hline 1590 & 1573 & 1590 & 1597 & & & $\delta(\mathrm{N}-\mathrm{H})$ \\
\hline 1552 & & 1585 & 1568 & 1537 & & amide II \\
\hline 1491 & & 1491 & 1455 & & & $\delta(\mathrm{C}-\mathrm{H})$ \\
\hline 1488 & 1467 & 1490 & & 1488 & & $\delta(\mathrm{C}-\mathrm{H})$ \\
\hline 1486 & 1456 & 1489 & & 1487 & & $\delta(\mathrm{N}-\mathrm{H})$ \\
\hline 1420 & 1413 & 1424 & 1401 & 1416 & 1407 & umbrella $\mathrm{CH}_{3}$ \\
\hline 1412 & 1400 & 1416 & & 1407 & & umbrella $\mathrm{CH}_{3}, \mathrm{COO}$ in phase \\
\hline 1394 & 1381 & 1402 & 1380 & 1395 & 1392 & $\delta(\alpha \mathrm{C}-\mathrm{H})$ \\
\hline 1245 & 1239 & 1275 & 1268 & 1230 & 1225 & $\delta(\alpha \mathrm{C}-\mathrm{H})$, amide III \\
\hline 1205 & 1171 & 1207 & 1220 & 1261 & 1266 & $\mathrm{~N}$-end, delocalized \\
\hline \multirow[t]{2}{*}{1143} & 1135 & 1177 & 1169 & 1146 & 1163 & $v(\mathrm{~N}-\alpha \mathrm{C}), \mathrm{CH}_{3}$ wagging \\
\hline & & 1134 & 1130 & & & $\delta(\mathrm{OH})$ in $\mathrm{COOH}$, delocalized \\
\hline 1106 & 1116 & 1112 & 1116 & 1136 & 1133 & $\mathrm{CH}_{3}$ wagging \\
\hline 1100 & 1102 & 1103 & & 1094 & 1102 & $\mathrm{NH}_{3}$ or $\mathrm{NH}_{2}$ wagging, $\mathrm{CH}_{3}$ wagging \\
\hline 1092 & 1066 & 1099 & 1102 & 1080 & 1086,1067 & $v(\mathrm{C}-\mathrm{C})$, delocalized \\
\hline 1065 & 1049 & 1067 & 1053 & 1066 & 1047 & $v(\mathrm{C}-\mathrm{C}), \mathrm{CH}_{3}$ \\
\hline 978 & 1011 & 980 & 1003 & 1013 & 1022 & $\mathrm{NH}_{3}$ or $\mathrm{NH}_{2}$ wagging, $\mathrm{CH}_{3}$ wagging \\
\hline 965 & 954,959 & 965 & 953 & 952 & 951 & $\mathrm{NH}_{3}$ or $\mathrm{NH}_{2}$ wagging, $\mathrm{CH}_{3}$ wagging \\
\hline \multirow[t]{2}{*}{947} & 925,927 & 951 & 927 & 915 & 923 & $v(\mathrm{C}-\mathrm{CO})$, delocalized \\
\hline & & & & 906 & & $\mathrm{NH}_{2}$ wagging \\
\hline 911 & 881 & 915 & & 891 & 883 & $v(\mathrm{C}-\mathrm{C})$ \\
\hline 570 & & 548 & 528 & & & delocalized, $\mathrm{OH}$ torsion \\
\hline 428 & 456 & 425 & & 450 & 461 & delocalized \\
\hline 427 & 369 & 419 & 452 & 426 & 381 & delocalized \\
\hline 336 & 345 & 342 & 362 & 332 & 334 & delocalized \\
\hline 308 & & 305 & 346 & 307 & & delocalized \\
\hline \multirow[t]{2}{*}{297} & & 297 & $251 ?$ & 303 & & delocalized \\
\hline & & & & 267 & 265 & $\mathrm{NH}_{2}$ wagging, delocalized \\
\hline 230 & 249 & 232 & & 234 & 237 & $\mathrm{CH}_{3}$ rot. \\
\hline
\end{tabular}

${ }^{a}$ Numbers in italics correspond to ROA peaks, and normal font is used for Raman.

water vibrations ${ }^{44}$ and thus are relatively insensitive to the mass of the backbone.

In the ROA spectra the isotopic substitution causes exceptional sign flips, such as that for the $\mathrm{C}-\mathrm{C}$ stretching band $(\sim 880$ $\left.\mathrm{cm}^{-1}\right)$, the amide III $\left(\sim 1275 \mathrm{~cm}^{-1}\right)$, and $\mathrm{C}-\mathrm{H}$ bending $(\sim 1400$ $\mathrm{cm}^{-1}$ ) signals. The computed spectra (Figure 2 ) well reproduce most of these wavenumber and intensity changes; however, for unresolved transitions, particularly in the $\mathrm{C}-\mathrm{H}$ bending region $\left(\sim 1250-1500 \mathrm{~cm}^{-1}\right)$, the predicted intensities somewhat deviate from the experiment. The amide II mode $\left(\sim 1550 \mathrm{~cm}^{-1}\right)$ remains hidden in both natural and labeled molecules.

The frequency changes observed under the isotopic substitution are well reproduced by the computed force fields. The shifts of most intense bands calculated at four levels, B3LYP/6$31+\mathrm{G}^{* *}, \mathrm{~B} 3 \mathrm{LYP} / \mathrm{aug}-\mathrm{cc}-\mathrm{pVTZ}, \mathrm{BPW} 91 / 6-31+\mathrm{G}^{* *}$, and MP2/ $6-31+\mathrm{G}^{* *}$, are compared to the experimental ones in Figure 3.
The default CPCM solvent model was used for the modeling. We can see that all the approximation levels provide similar (average absolute deviation was calculated as $\sim 5 \mathrm{~cm}^{-1}$ for all the four cases) and very reasonable prediction of the isotopic effects. As the shifts are not uniform, they can clearly be used for the verification of the assignment. For the bands at 1116 and $249 \mathrm{~cm}^{-1}$, the observed shifts are much larger (by $\sim 50 \%$ ) than predicted, which can be caused by a mode coupling insufficiently reproduced by the computation or by anharmonic forces. ${ }^{39}$ The bands involve namely the $\mathrm{CH}_{3}$ group (cf. Table 2), rotation of which cannot be reasonably reproduced at the harmonic level either. The $249 \mathrm{~cm}^{-1}$ band is probably also significantly influenced by coupling with water vibrations. ${ }^{44}$

Functional and Basis Set Dependence. In Figure 4 the AAZW Raman and ROA spectra calculated in small (6$31+\mathrm{G}^{* *}$ ) and larger (aug-cc-pvtz FOR Raman and $6-31+\mathrm{G}^{* *}$ 


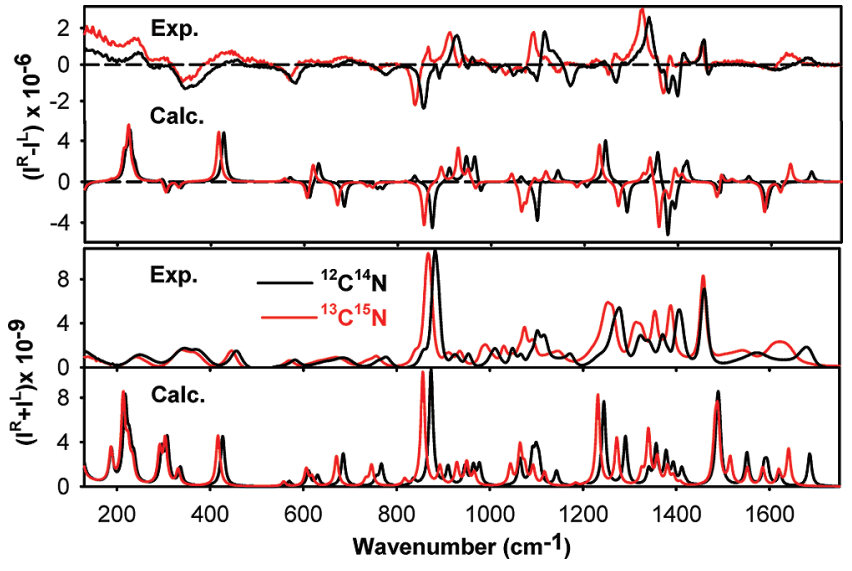

Figure 2. Experimental and computed ROA (top) and Raman (bottom) spectra of the natural (black) and ${ }^{13} \mathrm{C}^{15} \mathrm{~N}$-labeled (red) Ala-Ala zwitterion.

for ROA intensities) basis sets at the B3LYP level and the BPW91/6-31+G** and MP2/B3LYP/6-31+G** results, all with $\mathrm{CPCM}\left(\mathrm{H}_{2} \mathrm{O}\right)$, are compared to the experiment. For the larger basis only the local parts of the $\mathbf{A}$ and $\mathbf{G}^{\prime}$ tensors ${ }^{1,44-46}$ were obtained with the $6-31+\mathrm{G}^{* *}$ basis.

The basis set changes seem to cause negligible effects in the spectra, which somewhat contradicts previous works, where vibrational optical activity was simulated with smaller basis sets. $^{22,47,48}$ For example, the ROA couplet at $\sim 858 / 927 \mathrm{~cm}^{-1}$ and the " +-+ " pattern at $\sim 1336 / 1397 / 1453 \mathrm{~cm}^{-1}$ easily recognizable in the experiment are quite stable in the calculations. Thus, the $6-31+\mathrm{G}^{* *}$ basis appears to be large enough for reliable results, providing a balanced contribution of the diffuse and core electrons as discussed in detail in ref 49. However, the diffuse functions $(+)$ make a notable difference in ROA spectra if compared, for example, to the common $6-31 G^{* *}{ }^{16,44}$ A closer inspection of the spectra in Figure 4 nevertheless reveals differences in intensities of many ROA bands, even though the spectral shapes are similar. The ROA signal around $1100 \mathrm{~cm}^{-1}$ is particularly vulnerable to the approximation (the intensity changes up to $\sim 3$ times for the $6-31+\mathrm{G}^{* *} \rightarrow$ aug-cc-pvtz alteration), which may be in part responsible for discrepancies between the simulation and experiment in this region.

Modern DFT functionals provide comparable Raman and ROA spectral patterns, mostly with tiny differences in frequen- cies and intensities only. ${ }^{39}$ This is true also for the B3LYP and BPW91 computations compared in Figure 4. The BPW91 functional in smaller basis sets gives a better amide I ( 1650 $\left.\mathrm{cm}^{-1}\right)$ frequency than B3LYP $\left(\sim 1690 \mathrm{~cm}^{-1}\right)$, which is very convenient for IR amide I peptide studies. ${ }^{41,50,51}$ But this convenience vanishes in the Raman spectroscopy, where the structural information is encoded in many other vibrational transitions. The B3LYP frequencies appear better on average; typically, the BPW91 peak positions are predicted to be too low, including the strongest ROA and Raman bands. The MP2 amide I frequency is too high; otherwise, this approximation provides spectra very similar to those obtained by B3LYP. Some differences appear in signs of weak ROA bands; none of the levels reproduces all experimental spectral features. Overall, the B3LYP level used as a default seems to provide a well-balanced model in terms of the agreement with the experiment and the computational cost.

Solvent Model. Although previous studies indicate that explicit hydrogen-bond water molecules should be considered for the modeling of peptide properties, ${ }^{17,52,53}$ this is currently limited by the computational demands associated with ROA. Nevertheless, we can estimate the role of the hydrogen bonding on the AAZW spectra obtained as an average from ten dipeptide-water clusters, which are compared to the CPCM model and experiment in Figure 5. Within $\sim 800-1800 \mathrm{~cm}^{-1}$ the water signal does not interfere too much with that of the peptide, and the explicit waters cause a more realistic inhomogeneous broadening of the Raman bands in comparison with the plain CPCM model. This is apparent namely in the $\mathrm{NH}$ bending and $\mathrm{C}=\mathrm{O}$ stretching region $\left(1500-1800 \mathrm{~cm}^{-1}\right)$ and around $1100 \mathrm{~cm}^{-1}$. Within $\sim 1300-1450 \mathrm{~cm}^{-1}$ the broadening is larger than observed experimentally. The lower 200-800 $\mathrm{cm}^{-1}$ region is dominated by the water signal, which is difficult to separate from that of the peptide. An improvement would also perhaps require a larger number of clusters, which is not currently feasible, as about a month of computational time is needed for one ROA computation on a usual (64 bit AMD, 2 $\mathrm{GHz}$ ) processor.

The ROA signals in the upper panel in Figure 5 behave similarly as the Raman spectra; however, larger error is introduced by the explicit model, so many ROA bands realistically predicted by CPCM are destroyed. Nevertheless, we obtained at least qualitative information on the behavior of the solvated peptide that should be considered in the future: a larger

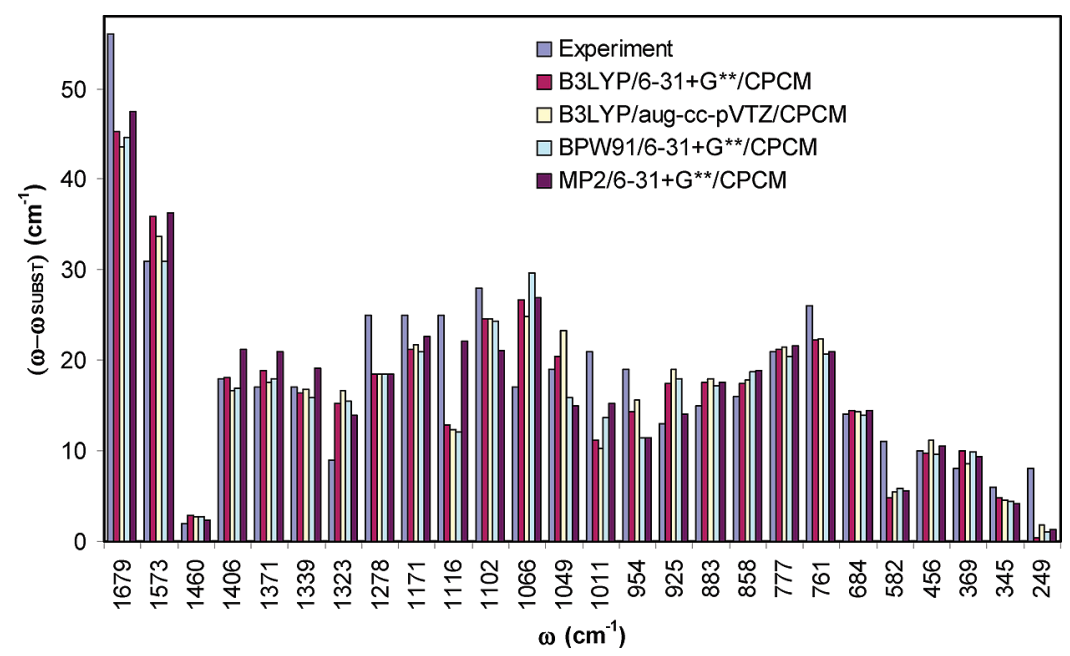

Figure 3. Experimental and calculated isotopic vibrational wavenumber shifts under the ${ }^{13} \mathrm{C}^{15} \mathrm{~N}$ substitution in AAZW. Experimental wavenumbers $(\omega)$ for the natural form are indicated on the horizontal axis. 


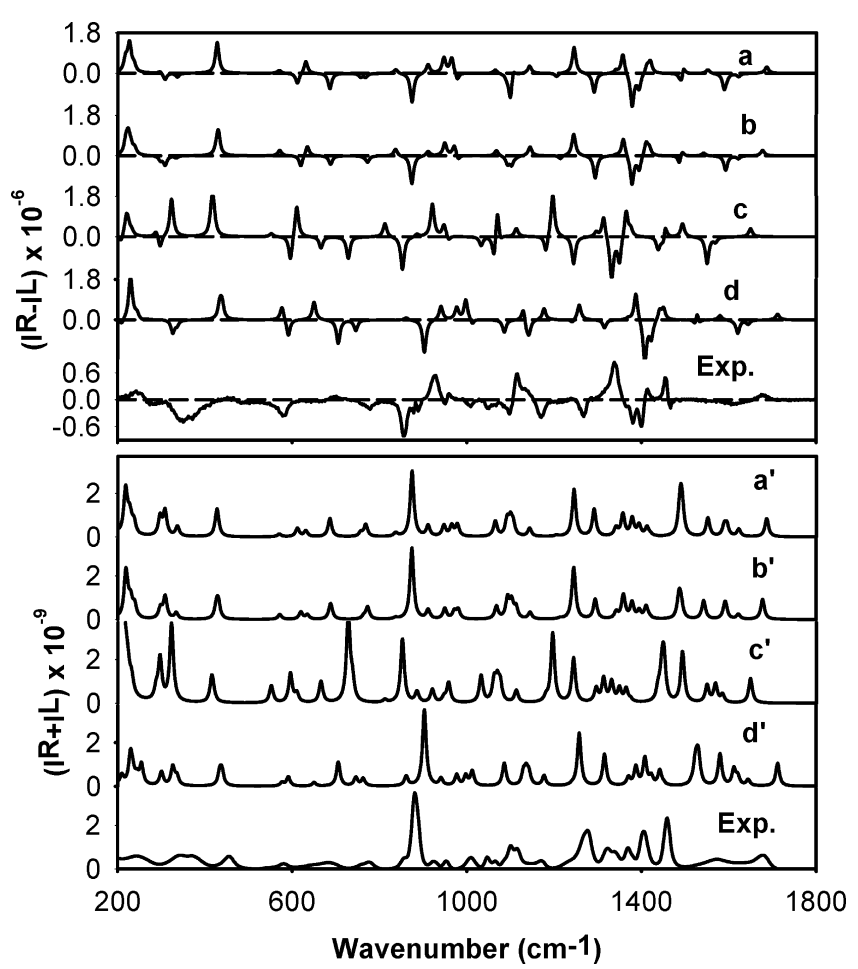

Figure 4. ROA (top) and Raman (bottom) AAZW spectra calculated at (a) B3LYP/6-31+G**, (b) B3LYP/aug-cc-pvtz ( $\mathbf{G}^{\prime}$ and $\mathbf{A}$ tensors with 6-31+G**), (c) BPW91/6-31+G**, and (d) MP2/6-31+G** $\left(\mathbf{G}^{\prime}\right.$ and $\mathbf{A}$ with B3LYP) levels and the experimental spectra. All calculations used the CPCM solvent model.
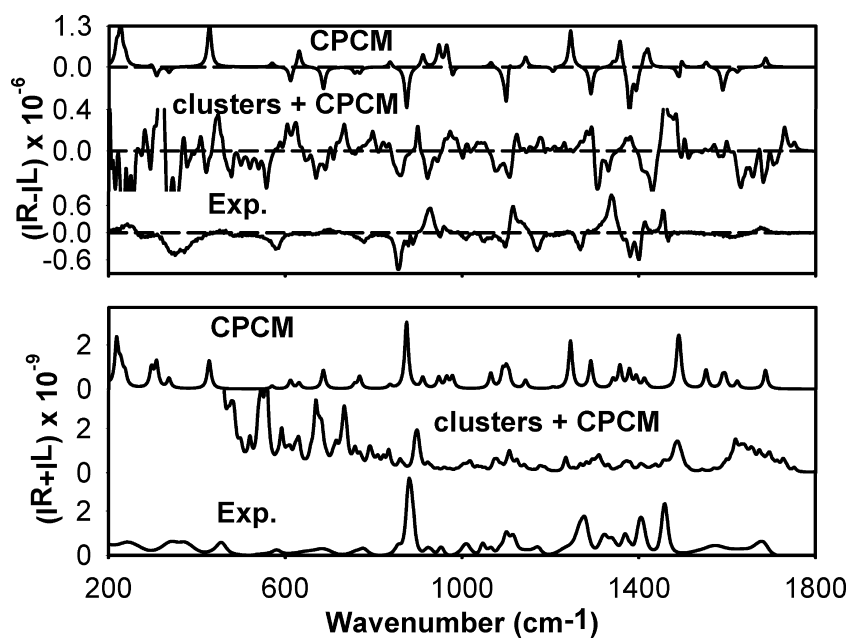

Figure 5. AAZW ROA (top) and Raman (bottom) spectra as calculated with the implicit CPCM and cluster solvent models and the experimental spectra. The B3LYP/6-31+G** level was used in the computations, and the clusters were submerged in the CPCM continuum as well; a simplified basis (6-31G) was used for the water molecules, and the local parts of the $\mathbf{A}$ and $\mathbf{G}^{\prime}$ tensors were obtained on the HF/6-31G level only for the dipeptide without waters.

number of clusters is needed to obtain a realistic ROA pattern in the lower $\left(<800 \mathrm{~cm}^{-1}\right)$ frequency region, and the hydration also decreases the ROA/Raman signal ratio (to $\sim 2 \times 10^{-4}$; compare the intensity scales in Figure 5), making the cluster relative ROA intensities more realistic on average.

AAZW Spectra. The present results and reasonable agreement between the simulated and experimental ROA and Raman spectra (cf. Figures 3-5) spectra are consistent with the previous works on AAZW ${ }^{10,12,13,16,27,54}$ and support the dominance of one backbone conformer in the solution. Attempts to vary the lowest-

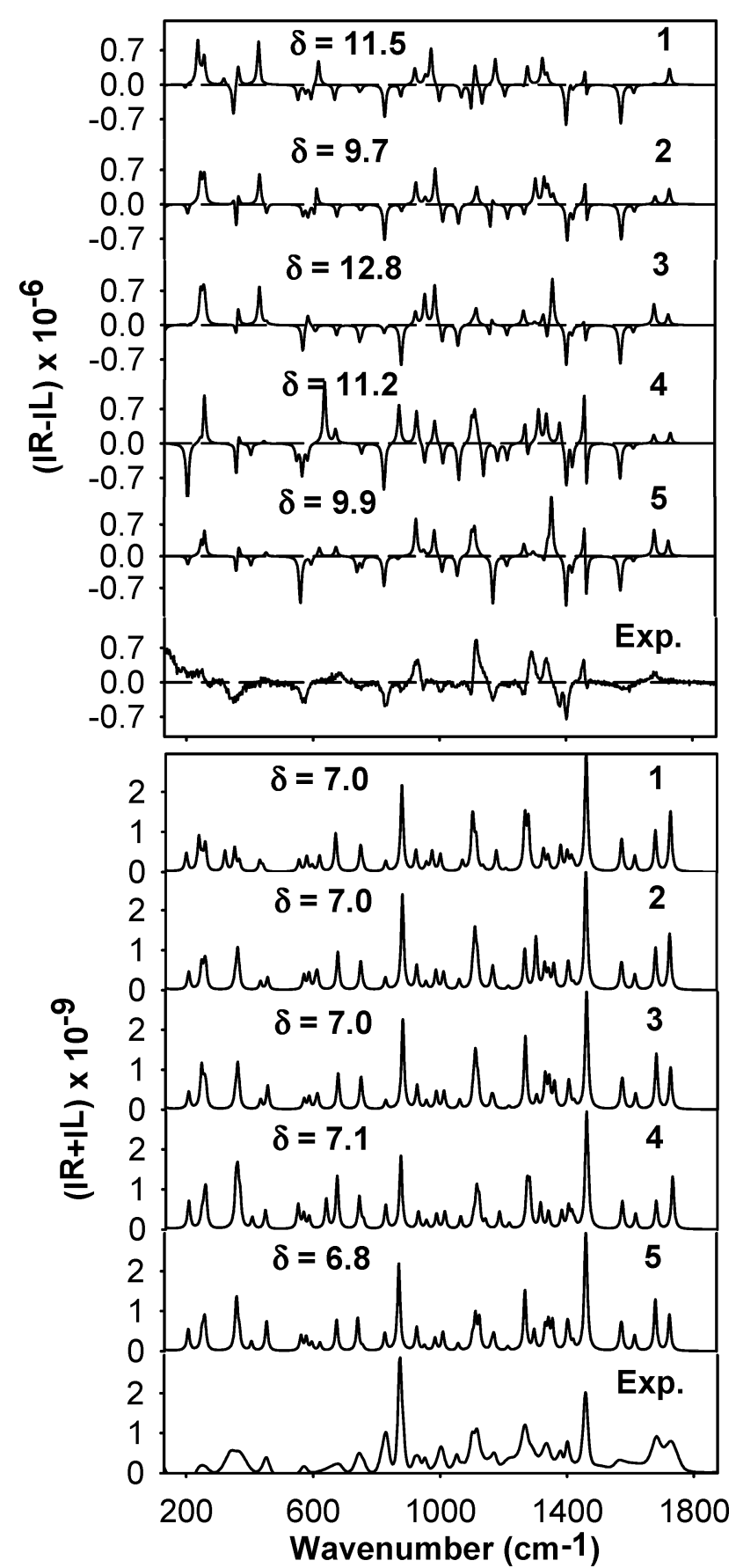

Figure 6. ROA (top) and Raman (bottom) spectra of the five $\mathbf{A A}^{+}$ conformations calculated at the B3LYP/CPCM/6-31+G** (scaled force field) level and the experimental spectra.

energy conformation in Table 1 did not bring a convincing improvement of the spectra and are not shown.

$\mathbf{A A}^{+}$Conformation. The low relative conformer energies in Table 1 indicate that the cation might exist in an ensemble of similar conformers. The sensitivity of the Raman and ROA spectra to the geometry variations is shown in Figure 6, where the calculated curves (B3LYP/CPCM/6-31+G**) are compared to the experiment. The Raman intensities vary slightly under the geometry changes, and although the technique has a potential to distinguish various conformers, definite conclusions cannot be made because of the limited precision of the computations and inhomogeneous broadening of the experimental spectral lines. Existence of the predicted splitting of the signal at 450 $\mathrm{cm}^{-1}$ is difficult to decide experimentally, but the presence of 


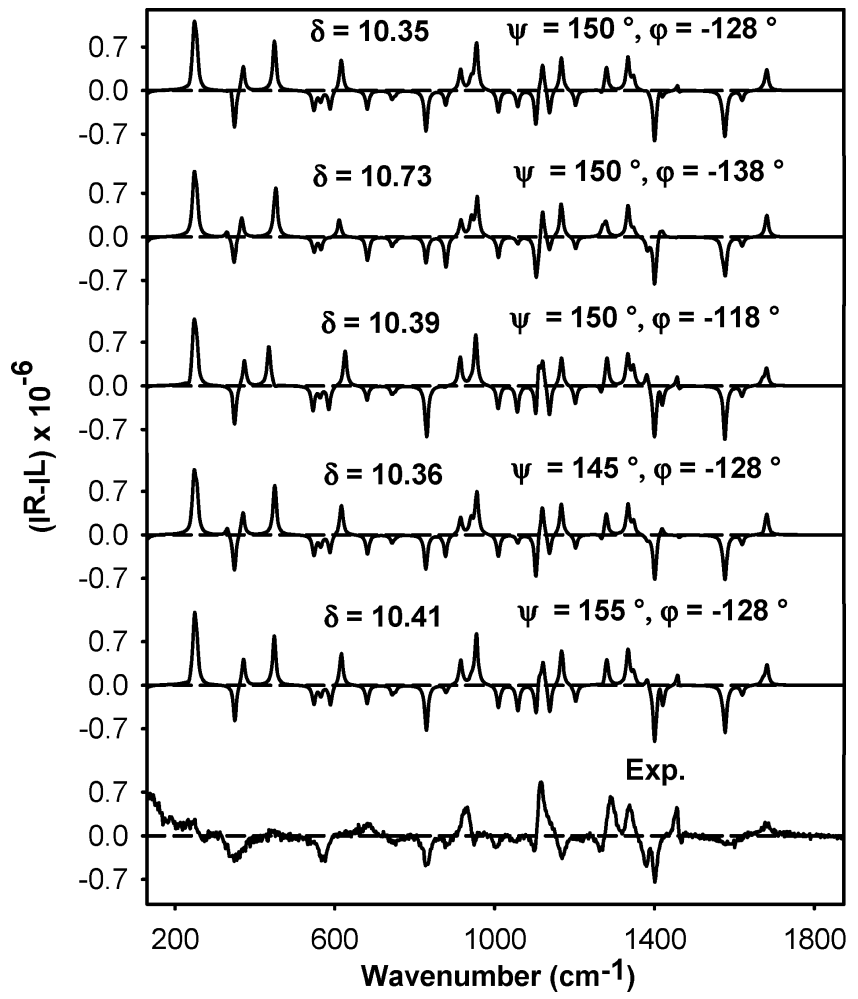

Figure 7. $\mathrm{AA}^{+} \mathrm{ROA}$ spectra simulated for five conformers (B3LYP/ CPCM/6-31+G**, scaled FF, the angles $\varphi$ and $\psi$ are indicated) and the experimental spectrum. $\delta$ is the root-mean-square deviation between the simulation and the experiment defined in the text.

the $\mathbf{4}$ and $\mathbf{5}$ forms cannot be excluded, as their relative energies (Table 1$)$ and the deviations from the spectra $(\delta$, Figure 6$)$ are small. The $\mathbf{3}$ and $\mathbf{5}$ conformers provide the correct relative intensity ordering of the highest-frequency bands at 1727/1682 $\mathrm{cm}^{-1}$.

Larger relative intensity variations under the geometry changes are visible in the ROA spectra in Figure 6. For example, the $\mathbf{1} \rightarrow \mathbf{2}$ change (the $\varphi$-angle changes by $24^{\circ}$ ) is accompanied by a transformation of the predominantly positive signal at 1458 $\mathrm{cm}^{-1}$ to a conservative couplet and a simplification of the ROA pattern at $\sim 1100 \mathrm{~cm}^{-1}$, both in favor of agreement with the experiment. A further change of the $\varphi$-angle (to $-94^{\circ}$ in 4) makes the agreement in the two regions and also around $\sim 950$ $\mathrm{cm}^{-1}$ worse again. The conformers $\mathbf{3}$ and $\mathbf{4}$ have a distinct \pm pattern at $\sim 1400 \mathrm{~cm}^{-1}$, which, however, does not seem to be present in the experiment. The simulated Raman and ROA spectra of the lowest-energy structure $\mathbf{1}$ and its slightly distorted variant 2 (cf. Table 1) thus seem to provide a very good agreement, similarly as for the zwitterion, yielding correct relative Raman intensities and correct ROA signs of most bands.

The $\mathbf{A A}{ }^{+}$ROA spectral pattern is thus consistent with the broad $\varphi$-potential well that enables a limited flexibility of the molecule. To explore fine modifications in the equilibrium structure, we varied the $\varphi$ and $\psi$ backbone torsion angles in smaller intervals and generated spectra for the resultant structures (using transferred tensors from the equilibrium). Then the average root-mean-square deviation between the simulation and experiment was calculated. From the spectra and deviations shown in Figure 7 we see that only minor or no improvement is achieved by increasing the $\psi$-angle (to $155^{\circ}$ ) and $\varphi$-angle (to $-118^{\circ}$ ), but this is consistent with the changes of individual peak intensities discussed in Figure 6. On the other hand, if $\varphi$ $=-138^{\circ}$ (approaching the value in AAZW) the deviation
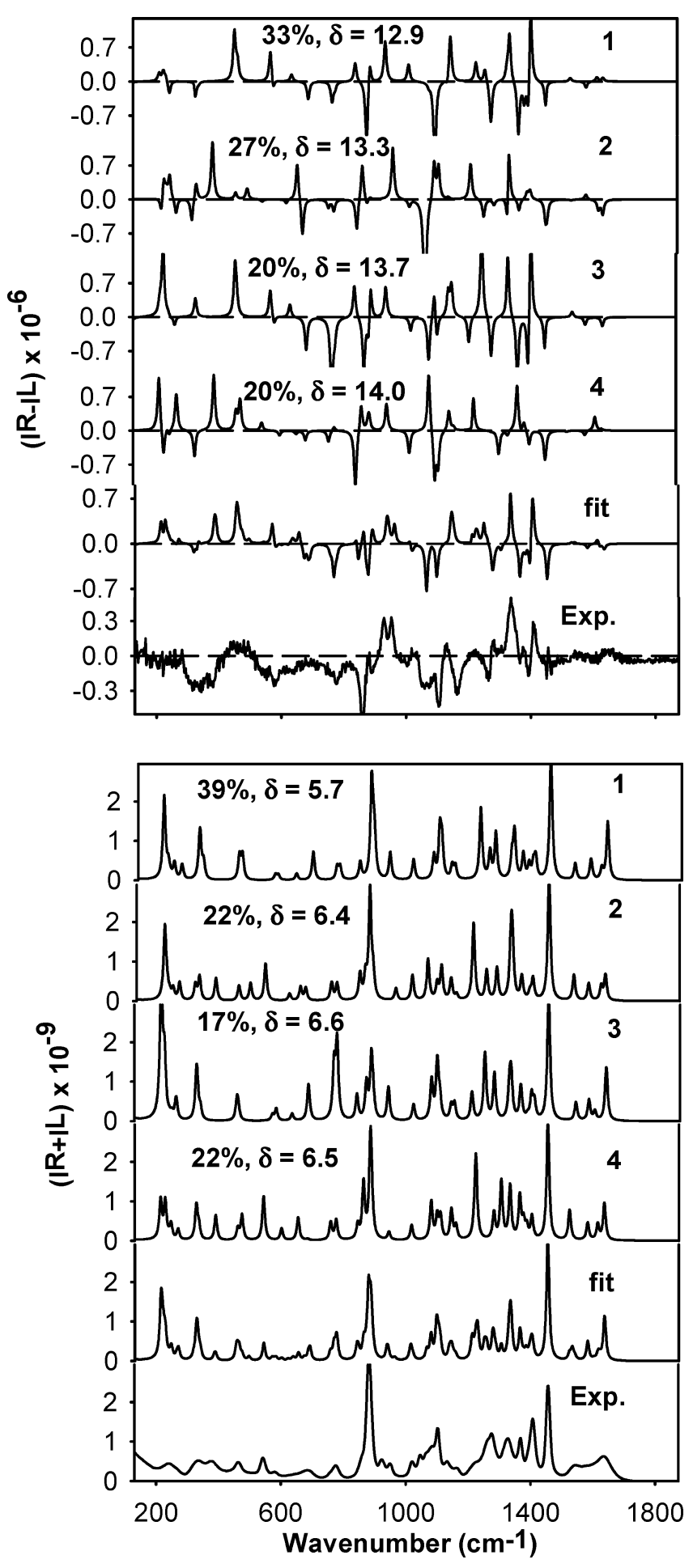

Figure 8. ROA (top) and Raman (bottom) spectra of four $\mathrm{AA}^{-}$ conformations (see Table 1) calculated at the B3LYP/CPCM/6-31+G** (scaled FF) level and the experimental spectra. The decomposition coefficients (in percent) and rms deviations obtained by the fit are indicated.

significantly increases. Thus, the ROA spectral analysis is consistent with the geometry determined as a minimum on the potential energy surface. The protonation of the zwitterion does not significantly change the $\psi$-backbone angle, while the $\varphi$-angle closer to the carboxyl residue changes by about $30^{\circ}$. The low $\mathrm{pH}$ thus abolishes the attraction between the $\mathrm{NH}_{3}{ }^{+}$and carboxylic groups that stabilizes the AAZW equilibrium structure in water. 

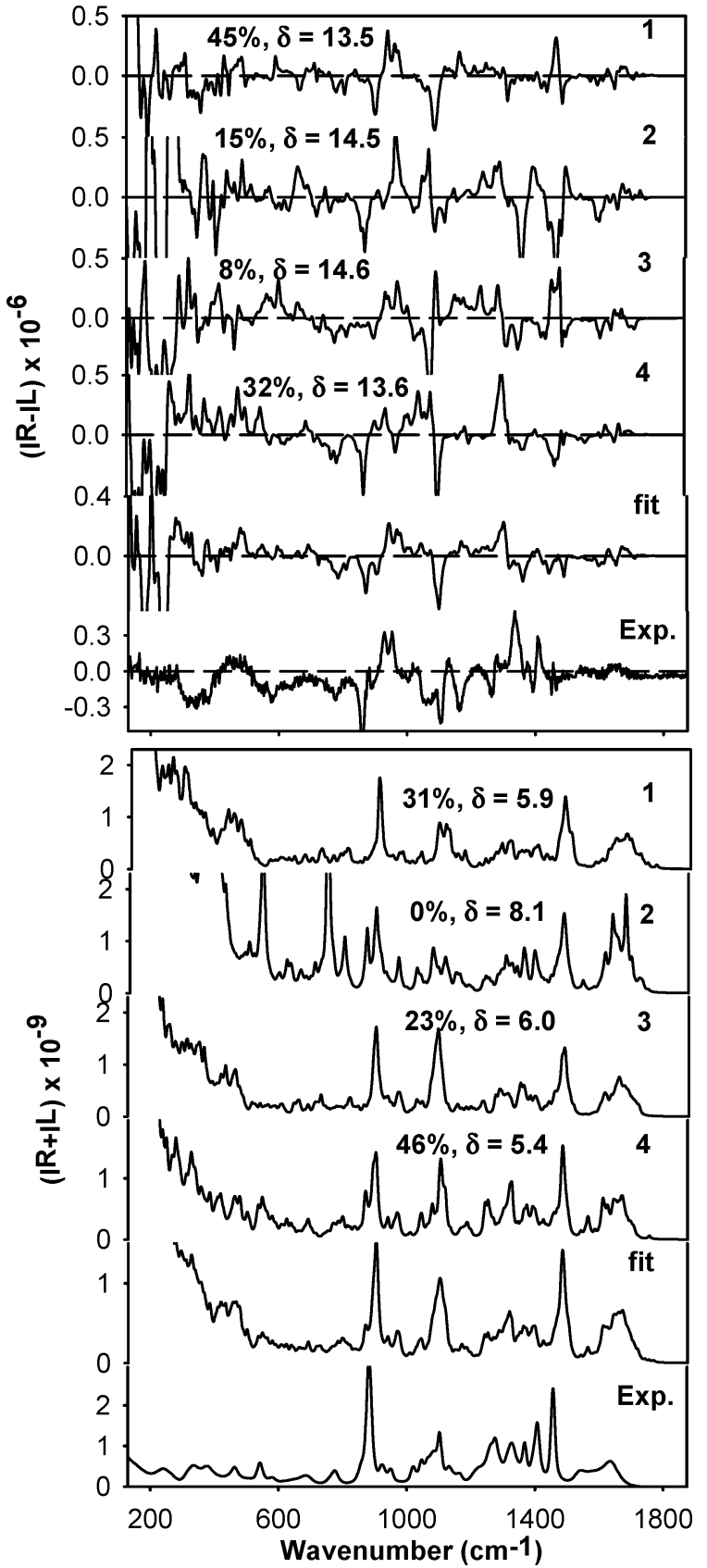

Figure 9. ROA (top) and Raman (bottom) spectra of the four $\mathrm{AA}^{-}$ conformations calculated from clusters with explicit water molecules (the spectral layout is the same as in Figure 8).

$\mathbf{A A}^{-}$Conformational Equilibrium. The conformational behavior of the anionic form is complicated by the rotation of the $\mathrm{NH}_{2}$ group that is coupled with the $\psi$-backbone conformational coordinate..$^{10}$ On the other hand, the equilibrium $\varphi$-angle is similar as in AAZW (cf. Table 1). The ROA and Raman spectra simulated for the four $\mathrm{AA}^{-}$lowest-energy conformers are compared to the experiment in Figure 8. We can see that conformer 1 provides the best agreement, as the rms deviations (see $\delta$ in the Figure) are low both for Raman and ROA. On the other hand, all experimental features cannot be explained with the one-conformer model, and a fit using all the four conformations provides much better representation, especially for the experimental ROA signal. For example, the ROA relative intensity within $150-600 \mathrm{~cm}^{-1}$ becomes smaller, and the negative signal at $\sim 1100 \mathrm{~cm}^{-1}$ splits, in favor of the experiment. In a relatively short range of frequencies from 1200 to 1300 $\mathrm{cm}^{-1}$, the agreement is still not satisfactory for reasons that we cannot currently explain. Overall, however, the spectral analysis is consistent with the previous NMR and CD results, indicating a multiconformational equilibrium for $\mathrm{AA}^{-},{ }^{10,12}$ although the calculated relative conformer energies and derived conformer ratios may not be reliable. The populations of the prevalent conformer 1 obtained from the decompositions of the ROA and Raman spectra (33 and 39\%, respectively) are in reasonable agreement. The accuracy is limited by the experimental deficiencies and inaccurate intensity modeling but is consistent with that observed in similar ROA conformation studies., ${ }^{9,20}$

As for the AAZW (Figure 5) and $\mathrm{AA}^{+}$(data not shown) the cluster averaging provides a more realistic inhomogeneous band broadening for $\mathrm{AA}^{-}$, as can be estimated from the ROA and Raman averaged spectra in Figure 9. However, the cluster model seems to overestimate the effect of water on the spectra and also somewhat affects the decomposition and resultant relative conformer ratios. The conformer populations obtained in Figure 8 appear more realistic, because the frequencies obtained with the CPCM solvent model could be scaled and corresponding experimental and calculated intensities could be compared more reliably. On the other hand, the explicit water model gives better frequencies that do not need scaling.

In some sense the present results indicate the need for a "medium" model comprising both the continuum and discrete character of the solvent and the system dynamics. The inclusions of finer effects of solvent and conformational freedom thus reveal new limitations of current computational techniques. Nevertheless, we believe that future enhancements based on a speeding of the ROA intensity computations ${ }^{55}$ or a timedependent spectral simulation technique ${ }^{56-58}$ can reveal even finer details in molecular structure and interactions.

\section{Conclusions}

We have synthesized Ala-Ala peptide labeled by stable isotopes to obtain vibrational frequency shifts that could be compared to the natural form. An excellent agreement between the observed and calculated shifts was achieved. This complementary information could be used for a more reliable assignment of experimental dialanine bands and a consequent scaling of the frequencies calculated with a continuum solvent model. An alternative cluster model provided more realistic inhomogeneous band broadening and improved in particular the Raman spectral features but introduced some errors in the ROA intensities. The modeling well-reproduced the differences observed in experimental spectra of the neutral, anionic, and cationic dipeptide forms and confirmed changes in their backbone structure previously indicated by DFT, CD, and NMR. Also the resultant conformer ratios are consistent with results obtained with the aid of NMR and CD spectroscopies. In comparison with these two techniques, the ROA spectra were found to be more sensitive to AA structural features. The statistical decomposition of the experimental spectra into calculated scaled subspectra provided more detailed and objective information about molecular structure than a visual comparison.

Acknowledgment. The work was supported by the Grant Agency of the Czech Republic (grants 202/07/0732 and 203/ 07/1517) and the Grant Agency of the Academy of Sciences (A400550702).

\section{References and Notes}

(1) Barron, L. D. Molecular Light Scattering and Optical Activity; Cambridge University Press: Cambridge, 2004. 
(2) Barron, L. D.; Hecht, L.; Bell, A. D. Vibrational Raman Optical Activity of Biomolecules. In Circular Dichroism and the Conformational Analysis of Biomolecules; Fasman, G. D., Ed.; Plenum: New York, 1996; pp 653.

(3) Keiderling, T. A. Curr. Opin. Chem. Biol. 2002, 6, 682.

(4) Barron, L. D.; Hecht, L. Biomolecular conformational studies with vibrational Raman optical activity. In Biomolecular Spectroscopy; Clark, R. J. H., Hester, R. E., Eds.; Wiley: Chichester, 1993; Part B, pp 235.

(5) Freedman, T. B.; Nafie, L. A.; Keiderling, T. A. Biopolymers 1995, 37,265

(6) Nafie, L. A. Appl. Spectrosc. 1996, 50, A14.

(7) Barron, L. D.; Hecht, L. Vibrational Raman optical activity: From fundamentals to biochemical applications. In Circular Dichroism, Principles and Applications; Nakanishi, K., Berova, N., Woody, R. W., Eds.; VCH Publishers: New York, 1994; pp 179.

(8) Kapitán, J.; Baumruk, V.; Kopecký, V., Jr.; Bouř, P. J. Phys. Chem. A 2006, 110, 4689.

(9) Buděšínský, M.; Daněček, P.; Bednárová, L.; Kapitán, J.; Baumruk, V.; Bouř, P. J. Phys. Chem. A 2008, 112, 8633.

(10) Sychrovský, V.; Buděšínský, M.; Benda, L.; Špirko, V.; Vokáčová, Z.; Šebestík, J.; Bouř, P. J. Phys. Chem. B 2008, 112, 1796.

(11) Zuk, W. M.; Freedman, T. B.; Nafie, L. A. Biopolymers 1989, 28, 2025.

(12) Šebek, J.; Gyurscik, B.; Šebestík, J.; Kejík, Z.; Bernárová, L.; Bouř, P. J. Phys. Chem. A 2007, 111, 2750.

(13) Jalkanen, K. J.; Nieminen, R. M.; Knapp-Mohammady, M.; Suhai,

S. Int. J. Quantum Chem. 2003, 92, 239.

(14) Lucas, B.; Gregoire, H.; Maitre, P.; Ortega, J. M.; Rupenyan, A.; Reimann, B.; Scherman, J. P.; Desfrancois, C. Phys. Chem. Chem. Phys. 2004, 6, 2659 .

(15) Diem, M.; Lee, O.; Roberts, G. M. J. Phys. Chem. 1992, 96, 548

(16) Bouř, P.; Kapitán, J.; Baumruk, V. J. Phys. Chem. A 2001, 105, 6362 .

(17) Knapp-Mohammady, M.; Jalkanen, K. J.; Nardi, F.; Wade, R. C.; Suhai, S. Chem. Phys. 1999, 240, 63.

(18) Weir, A. F.; Lowrey, A. H.; Williams, R. W. Biopolymers 2001, 58,577

(19) Mukhopadhyay, P.; Zuber, G.; Beratan, D. N Biophys. J. 2008, 95, 5574 .

(20) Buděšínský, M.; Šebestík, J.; Bednárová, L.; Baumruk, V.; Šafařík, M.; Bouř, P. J. Org. Chem. 2008, 73, 1481.

(21) Cuperlovic, M.; Meresi, G. H.; Palke, W. E.; Gering, J. T. J. Magn. Reson. 2000, 142, 11.

(22) Ruud, K.; Helgaker, T.; Bouř, P. J. Phys. Chem. A 2002, 106, 7448.

(23) Polavarapu, P. L. Vibrational spectra: Principles and Applications with Emphasis on Optical Activity; Elsevier: Amsterdam, 1998; Vol. 85.

(24) Cheng, L.; Goodwin, C. A.; Schully, M. F.; Kakkar, V. V. J. Med. Chem. 1992, 35, 3364 .

(25) Wünsch, E.; Wendlberger, G.; Deimer, K. H. Hoppe Seylers Z. Physiol. Chem. 1976, 357, 447.

(26) Stein, W. H.; Moore, S.; Bergmann, M. J. Biol. Chem. 1944, 154, 191.

(27) Bouř, P.; Buděšínský, M.; Špirko, V.; Kapitán, J.; Šebestík, J.; Sychrovský, V. J. Am. Chem. Soc. 2005, 127, 17079.

(28) Hanzlíková, J.; Praus, P.; Baumruk, V. J. Mol. Struct. 1999, 481, 431.

(29) Kapitán, J.; Baumruk, V.; Hulačová, H.; Maloň, P. Vib. Spectrosc. 2006, 42,88

(30) Frisch, M. J.; Trucks, G. W.; Schlegel, H. B.; Scuseria, G. E.; Robb, M. A.; Cheeseman, J. R.; Montgomery, J., J. A.; Vreven, T.; Kudin, K. N. Burant, J. C.; Millam, J. M.; Iyengar, S. S.; Tomasi, J.; Barone, V.; Mennucci, B.; Cossi, M.; Scalmani, G.; Rega, N.; Petersson, G. A.;
Nakatsuji, H.; Hada, M.; Ehara, M.; Toyota, K.; Fukuda, R.; Hasegawa, J.; Ishida, M.; Nakajima, T.; Honda, Y.; Kitao, O.; Nakai, H.; Klene, M.; Li, X.; Knox, J. E.; Hratchian, H. P.; Cross, J. B.; Bakken, V.; Adamo, C.; Jaramillo, J.; Gomperts, R.; Stratmann, R. E.; Yazyev, O.; Austin, A. J.; Cammi, R.; Pomelli, C.; Ochterski, J. W.; Ayala, P. Y.; Morokuma, K.; Voth, G. A.; Salvador, P.; Dannenberg, J. J.; Zakrzewski, V. G.; Dapprich, S.; Daniels, A. D.; Strain, M. C.; Farkas, O.; Malick, D. K.; Rabuck, A. D.; Raghavachari, K.; Foresman, J. B.; Ortiz, J. V.; Cui, Q.; Baboul, A. G.; Clifford, S.; Cioslowski, J.; Stefanov, B. B.; Liu, G.; Liashenko, A.; Piskorz, P.; Komaromi, I.; Martin, R. L.; Fox, D. J.; Keith, T.; Al-Laham, M. A.; Peng, C. Y.; Nanayakkara, A.; Challacombe, M.; Gill, P. M. W.; Johnson, B.; Chen, W.; Wong, M. W.; Gonzalez, C.; Pople, J. A. Gaussian 03, Revision C.02; Gaussian, Inc.: Wallingford CT, 2004.

(31) Becke, A. Phys. Rev. A 1988, 38, 3098-3100.

(32) Becke, A. D. J. Chem. Phys. 1993, 98, 5648.

(33) Barone, V.; Cossi, M. J. Phys. Chem. 1998, 102, 1995.

(34) Klamt, A.; Schuurmann, G. J. Chem. Soc., Perkin Trans. 1993, 2, 799.

(35) Bouř, P.; Sopková, J.; Bednárová, L.; Maloň, P.; Keiderling, T. A. J. Comput. Chem. 1997, 18, 646.

(36) Bouř, P.; Keiderling, T. A. J. Chem. Phys. 2002, 117, 4126.

(37) Bouř, P. Collect. Czech. Chem. Commun. 2005, 70, 1315.

(38) Ahlrichs, R.; Bar, M.; Baron, H.-P.; Bauernschmitt, R.; Bocker, S.; Ehrig, M.; Eichkorn, K.; Elliot, S.; Furche, F.; Haase, F.; Haser, M.; Horn, H.; Huber, C.; Huniar, U.; Kattannek, M.; Kolmel, C.; Koolwitz, M.; May, K.; Ochsenfeld, C.; Ohm, H.; Schafer, A.; Schneider, U.; Treutler, O.; von Arnim, M.; Weigend, F.; Weis, P.; Weiss, H. Turbomole, version 5; Quantum Chemistry Group, University of Karlsruhe: Karlsruhe, 1998.

(39) Daněček, P.; Bouř, P. J. Chem. Phys. 2007, 126, 224513.

(40) Nafie, L. A. Annu. Rev. Phys. Chem. 1997, 48, 357.

(41) Bouř, P.; Keiderling, T. A. J. Phys. Chem. B 2005, 109, 5348.

(42) Setnička, V.; Huang, R.; Thomas, C. L.; Etienne, M. A.; Kubelka, J.; Hammer, R. P.; Keiderling, T. A. J. Am. Chem. Soc. 2005, 127, 4992. (43) Bouř, P.; Keiderling, T. A. J. Mol. Struct. (THEOCHEM) 2004, 675,95 .

(44) Kapitán, J.; Baumruk, V.; Kopecký, V., Jr.; Pohl, R.; Bouř, P. J. Am. Chem. Soc. 2006, 128, 13451.

(45) Bouř, P.; Baumruk, V.; Hanzlíková, J. Collect. Czech. Chem. Commun. 1997, 62, 1384.

(46) Bouř, P. J. Comput. Chem. 2001, 22, 426.

(47) Bak, K. L.; Jorgensen, P.; Helgaker, T.; Ruud, K. Faraday Discuss.

1994, 99, 121.

(48) Macleod, N. A.; Butz, P.; Simons, J. P.; Grant, G. H.; Baker, C. M.;

Tranter, G. E. Phys. Chem. Chem. Phys. 2005, 7, 1432.

(49) Zuber, G.; Hug, W. J. Phys. Chem. A 2004, 108, 2108.

(50) Bouř, P.; Keiderling, T. A. J. Phys. Chem. B 2005, 109, 23687.

(51) Huang, R.; Kubelka, J.; Barber-Armstrong, W.; Silva, R. A. G. D.;

Decatur, S. M.; Keiderling, T. A. J. Am. Chem. Soc. 2004, 126, 2346.

(52) Bouř, P.; Michalík, D.; Kapitán, J. J. Chem. Phys. 2005, 122, 144501.

(53) Yang, S.; Cho, M. J. Phys. Chem. B 2007, 111, 605.

(54) Mehta, M. A.; Fry, E. A.; Eddy, M. T.; Dedeo, M. T.; Anagnost,

A. E.; Long, J. R. J. Phys. Chem. B 2004, 108, 2777.

(55) Liegeois, V.; Ruud, K.; Champagne, B. J. Chem. Phys. 2007, 127, 204105.

(56) Choi, J. H.; Cho, M. H. J. Chem. Phys. 2009, 130, 014503.

(57) Kwac, K.; Lee, K. K.; Han, J.; Oh, K. I.; Cho, M. J. Chem. Phys. 2008, $128,105106$.

(58) Horníček, J.; Kaprálová, P.; Bouř, P. J. Chem. Phys. 2007, 127, 084502.

JP902739R 